\title{
Effect of Interleukin-1 Blockade with Anakinra on Leukocyte Count in Patients with ST-Segment Elevation Acute Myocardial Infarction
}

\section{MARCO GIUSEPPE DEL BUONO}

Virginia Commonwealth University

Juan Ignacio Damonte

Virginia Commonwealth University

Cory R Trankle

Virginia Commonwealth University

Dinesh Kadariya

Virginia Commonwealth University

Salvatore Carbone

Virginia Commonwealth University

Georgia K Thomas

Virginia Commonwealth University

Jeremy Turlington

Virginia Commonwealth University

Roshanak Markley

Virginia Commonwealth University

Justin Canada

Virginia Commonwealth University

Giuseppe Biondi-Zoccai

Sapienza University of Rome

Michael C. Kontos

Virginia Commonwealth University

Benjamin W. Van Tassell

Virginia Commonwealth University

Antonio Abbate ( $\square$ antonio.abbate@vcuhealth.org )

Virginia Commonwealth University

\section{Research Article}

Keywords: leukocyte, STEMI, neutrophils, anakinra, IL-1, cytokine, leukopoiesis, inflammation 
Posted Date: October 15th, 2021

DOl: https://doi.org/10.21203/rs.3.rs-959200/v1

License: (c) (i) This work is licensed under a Creative Commons Attribution 4.0 International License. Read Full License 


\section{Abstract}

Background. Leukocytosis is a common finding in patients with ST elevation myocardial infarction (STEMI) and portends a poor prognosis. Interleukin 1-b regulates leukopoiesis and pre-clinical studies suggest that anakinra (recombinant human interleukin-1 [IL-1] receptor antagonist) suppresses leukocytosis in myocardial infarction. However, the effect of IL-1 blockade with anakinra on leukocyte count in patients with STEMI is unknown.

Methods. We reviewed the white blood cell (WBC) and differential count of 99 patients enrolled in a clinical trial of anakinra $(n=64)$ versus placebo $(n=35)$ for 14 days after STEMI. A complete blood cell count with differential count were obtained at admission, and after 72 hours, 14 days and 3 months.

Results. After 72 hours from treatment, anakinra compared to placebo led to a statistically significant greater percent reduction in total WBC count (-35\% [-48 to -24] vs $-21 \%$ [-34 to -10$], P=0.008)$, absolute neutrophil count (-48\% [-60 to -22$]$ vs $-27 \%$ [-46 to -5$], P=0.004)$ and to an increase in absolute eosinophil count ( $+50 \%[0$ to +100$]$ vs $0 \%[-50$ to +62$], P=0.022)$. These changes persisted while on treatment at 14 days and were no longer apparent at 3 months after treatment discontinuation.

Conclusion. We found that in patients with STEMI IL-1 blockade with anakinra accelerates resolution of leukocytosis and neutrophilia. This modulation may represent one of the mechanisms by which IL-1 blockade improves clinical outcomes.

\section{Introduction}

ST-segment-elevation myocardial infarction (STEMI) is a leading cause of morbidity and mortality worldwide. Reperfusion strategies have revolutionized its treatment by reducing infarct size and improving survival (1). However, an inflammatory response is triggered by acute ischemia and amplified by the reperfusion, which contributes to cause further injury despite being essential for tissue healing (2). Elevated leukocyte count is a marker of inflammation and is associated with greater infarct size, reduced systolic function, and adverse clinical outcomes in patients with STEMI (3-6). In response to ischemic injury, the number of neutrophils in the blood increases rapidly and begin to appear in the infarcted tissue within hours. While neutrophils contribute to the clearance of pathogens or debris as well as coordinate the monocyte-derived macrophage infiltration that activate reparative pathways necessary for scar formation (7-9), perturbation of this finely regulated balance may lead to an exuberant and prolonged inflammatory state that acutely worsens the infarct size and chronically contributes to post-myocardial infarction adverse remodeling (10-13)

Interleukin 1- $\beta$ regulates leukopoiesis favoring a sustained neutrophil production in the bone marrow (8). In this regard, pre-clinical studies reported that anakinra (recombinant human interleukin-1 [IL-1] receptor antagonist) suppressed leukocytosis in mouse models of myocardial infarction suggesting its potential role in suppressing the leukopoiesis in the bone marrow and neutrophil recruitment within the heart (14). 
Data on the role IL-1 $\beta$ in patients with STEMI are limited. In a small pilot trial of anakinra in 10 patients with STEMI, patients treated with anakinra had significantly lower leukocyte and neutrophil counts 24 hours after the first injection compared to placebo-treated patients (15), and leukocytes from anakinratreated patients had reduced production of pro-inflammatory cytokines (16). In this study we describe the effect of IL-1 blockade on leukocyte count in patients with STEMI treated with one of two different doses of anakinra in the setting of a randomized double-blinded clinical trial.

\section{Methods}

\section{Study design}

In the Virginia Commonwealth University Anakinra Remodeling Trial (VCUART) 3 (www.clinicaltrials.gov NCT01950299) (17,18), 99 patients were randomly assigned to receive anakinra $100 \mathrm{mg}$ once daily (standard dose), alternating with placebo every 12 hours, for 14 days; anakinra, $100 \mathrm{mg}$ twice daily, every 12 hours (high dose) for 14 days; or placebo twice daily every 12 hours for 14 days, with the first dose administered within 12 hours of coronary angiography. Patients were excluded from the study if they had contraindications to treatment with anakinra, chronic inflammatory or infectious disease, or preexisting structural or functional severe cardiac abnormalities. For the purpose of this analysis, we pooled the two anakinra arms together, as previously presented for the clinical outcomes (17).

\section{Laboratory data}

The methods have been described in detail elsewhere $(17,18)$. A differential blood cell count was obtained at admission, and after 72 hours, 14 days and 3 months. Total white blood cell (WBC) count and neutrophil, lymphocyte, monocyte and eosinophil counts were calculated using a hematology analyzer. Neutrophil to lymphocyte ratio, calculated as total neutrophil counts divided by total lymphocyte counts, was computed from the absolute values of neutrophils and lymphocyte $(17,18)$.

\section{Statistical analysis}

The methods have been described in detail elsewhere $(17,18)$. Descriptive statistics were used to describe baseline and clinical characteristics of the patients. Categorical variables are presented as frequency (percentage) and compared using Chi-Square or Fisher's exact test as appropriate. Continuous variables are presented as median [interquartile range, IQR] and compared using Mann-Whitney U test or Spearman's rank test for correlations. There were no differences in the missing data between the groups; no missing data imputation was used. All analyses were completed using SPSS, version 24.0 (SPSS; Chicago, IL) with significance set at $a=0.05(17,18)$.

\section{Regulatory data}

All methods were carried out in accordance with relevant guidelines and regulations. All experimental protocols were approved by the Virginia Commonwealth University Institutional Review Board. All 
subjects provided written informed consent to be part of the trial in accordance with the Virginia Commonwealth University Institutional Review Board.

\section{Results}

\section{Baseline characteristics}

Baseline characteristics of the 99 patients have been previously reported (17) and are summarized in Table 1. Patients were predominantly male $(n=80,81 \%)$ with a median age of 55 [49.0-62.0] years. Patients were randomized to anakinra standard dose daily $(n=33,[33 \%])$, anakinra high dose $(n=31$, [31\%]), or placebo $(n=35,[35 \%])$. Clinical characteristics were well matched, without statistically significant differences between anakinra and placebo groups except for a higher prevalence of diabetes mellitus in the placebo compared to anakinra group (15 [43\%] vs 15 [23\%], p=0.044). There were no differences between the two groups in time from symptom onset to percutaneous coronary intervention, time from symptom onset to investigational drug administration, or periprocedural drugs received. There was no difference in infarct size between the two groups, while the under the curve for high sensitivity CReactive Protein (CRP) was significantly lower in patients receiving anakinra versus placebo (67 [39-120] vs 214 [131-394] mg.day/L, p<0.001) (Table 2). 
Table 1

Clinical characteristics of the patients in anakinra and placebo groups.

\begin{tabular}{|c|c|c|c|}
\hline & $\begin{array}{l}\text { Anakinra } \\
(n=64)\end{array}$ & $\begin{array}{l}\text { Placebo } \\
(n=35)\end{array}$ & $P$-value \\
\hline Age, y & $55[48-61]$ & $56[51-65]$ & 0.174 \\
\hline Female sex & $14(22)$ & $5(4)$ & 0.359 \\
\hline White & $36(56)$ & $21(60)$ & 0.223 \\
\hline Black & $21(33)$ & $6(17)$ & \\
\hline Hispanic & $2(3)$ & $3(9)$ & \\
\hline Other & $5(8)$ & $5(14)$ & \\
\hline \multicolumn{4}{|l|}{ Procedural characteristics } \\
\hline Symptom onset to $\mathrm{PCl}$, min & $\begin{array}{l}187[106- \\
333]\end{array}$ & $\begin{array}{l}180[130- \\
347]\end{array}$ & 0.801 \\
\hline $\begin{array}{l}\text { Symptom onset to investigational drug } \\
\text { administration, min }\end{array}$ & $\begin{array}{l}508[348- \\
718]\end{array}$ & $\begin{array}{l}529[403- \\
716]\end{array}$ & 0.669 \\
\hline Fibrinolytic use before PCl & $5(8)$ & $3(9)$ & 0.587 \\
\hline \multicolumn{4}{|l|}{ PCl type } \\
\hline Primary $\mathrm{PCl}$ & $59(92)$ & $32(91)$ & 0.587 \\
\hline $\mathrm{PCl}$ after fibrinolysis & $5(8)$ & $3(9)$ & 0.587 \\
\hline Use of drug-eluting-stent & $44(69)$ & $30(86)$ & 0.063 \\
\hline Use of thrombectomy & $10(16)$ & $6(17)$ & 0.844 \\
\hline Use of P2Y12 inhibitor & $64(100)$ & $35(100)$ & 1 \\
\hline Clopidogrel & $9(14)$ & $7(20)$ & \\
\hline Prasugrel & $22(34)$ & $12(34)$ & \\
\hline Ticagrelor & $33(52)$ & $15(46)$ & \\
\hline \multicolumn{4}{|l|}{ Clinical characteristics } \\
\hline Coronary artery disease & $14(22)$ & $7(20)$ & 0.827 \\
\hline Diabetes mellitus & $15(23)$ & $15(43)$ & 0.044 \\
\hline Systemic arterial hypertension & $33(52)$ & $23(66)$ & 0.174 \\
\hline
\end{tabular}

Abbreviations: STEMl: ST elevation myocardial infarction; PCl: percutaneous coronary intervention; Min: minutes; LVEF: left ventricle ejection fraction. 


\begin{tabular}{|lccc|}
\hline & $\begin{array}{l}\text { Anakinra } \\
(\mathbf{n = 6 4 )}\end{array}$ & $\begin{array}{l}\text { Placebo } \\
(\mathbf{n = 3 5 )}\end{array}$ & $P$-value \\
\hline Baseline LVEF, \% & $51[44-58]$ & $53[42-57]$ & 0.963 \\
\hline $\begin{array}{l}\text { Abbreviations: STEMI: ST elevation myocardial infarction; PCl: percutaneous coronary intervention; } \\
\text { Min: minutes; LVEF: left ventricle ejection fraction. }\end{array}$ & & \\
\hline
\end{tabular}


Table 2

Laboratory data according to anakinra and placebo.

\begin{tabular}{|c|c|c|c|}
\hline & $\begin{array}{l}\text { Anakinra } \\
(n=64)\end{array}$ & $\begin{array}{l}\text { Placebo } \\
(n=35)\end{array}$ & $P$-value \\
\hline CKMB-AUC, ng/mL*d & 2219 [1130-3821] & $2351[765-4668]$ & 0.859 \\
\hline \multicolumn{4}{|l|}{ At admission } \\
\hline Hemoglobin, g/dL & $14.5[13.4-15.3]$ & $14.4[13.6-15.6]$ & 0.692 \\
\hline Hematocrit, \% & $43[40-47]$ & $42[41-44]$ & 0.558 \\
\hline White blood cell, $10^{9} / \mathrm{L}$ & $10.85[8.52-13.90]$ & $11.40[9.20-15.07]$ & 0.692 \\
\hline Absolute neutrophil count, $10^{9} / \mathrm{L}$ & $7.45[4.72-11.05]$ & $7.30[5.20-12.50]$ & 0.622 \\
\hline Absolute lymphocyte count, $10^{9} / \mathrm{L}$ & $2.05[1.3-3.02]$ & $1.8[1.30-2.55]$ & 0.699 \\
\hline Absolute monocyte count, $10^{9} / \mathrm{L}$ & $0.60[0.40-0.80]$ & $0.70[.50-0.80]$ & 0.185 \\
\hline Absolute eosinophil count, $10^{9} / \mathrm{L}$ & $0.10[0.00-0.125]$ & $0.10[0.00-0.20]$ & 0.279 \\
\hline Neutrophil to lymphocyte ratio & $4.29[1.99-7.51]$ & $3.71[2.08-8.37]$ & 0.719 \\
\hline Creatinine, $\mathrm{mg} / \mathrm{dL}$ & $0.94[0.78-1.10]$ & $1.00[0.89-1.34]$ & 0.063 \\
\hline NTproBNP, pg/mL & $52.50[22.00-217.59]$ & $95.5[23.75-244.00]$ & 0.614 \\
\hline \multicolumn{4}{|l|}{ At 72 hours } \\
\hline White blood cell, $10^{9} / \mathrm{L}$ & $7.50[6.20-8.35]$ & $8.30[7.20-9.80]$ & \\
\hline$\%$ Change from baseline & $-35 \%[-48$ to -24$]$ & $-21 \%[-34$ to -10$]$ & 0.008 \\
\hline Absolute neutrophil count, $10^{9} / \mathrm{L}$ & $4.15[3.22-5.07]$ & $5.40[4.65-5.40]$ & \\
\hline$\%$ Change from baseline & $-48 \%[-60$ to -22$]$ & $-27 \%[-46$ to -5$]$ & 0.004 \\
\hline Absolute lymphocyte count, $10^{9} / \mathrm{L}$ & $2.15[1.50-2.60]$ & $1.80[1.40-2.20]$ & \\
\hline$\%$ Change from baseline & $-7 \%[-4 \%$ to +32$]$ & $-6 \%[-38$ to +22$]$ & 0.657 \\
\hline Absolute monocyte count, $10^{9} / \mathrm{L}$ & $0.60[0.50-0.80]$ & $0.80[0.60-0.95]$ & \\
\hline$\%$ Change from baseline & $+11 \%[-29$ to +51$]$ & $+14 \%[-13$ to +47$]$ & 0.604 \\
\hline Absolute eosinophil count, $10^{9} / \mathrm{L}$ & $0.20[0.10-0.30]$ & $0.10[0.10-0.30]$ & \\
\hline$\%$ Change from baseline & $+50 \%[0$ to +100$]$ & $0 \%[-50$ to +62$]$ & 0.022 \\
\hline Neutrophil to lymphocyte ratio & $1.90[1.37-3.22]$ & $3.35[2.6$ & \\
\hline
\end{tabular}




\begin{tabular}{|c|c|c|c|}
\hline & $\begin{array}{l}\text { Anakinra } \\
(n=64)\end{array}$ & $\begin{array}{l}\text { Placebo } \\
(n=35)\end{array}$ & $P$-value \\
\hline$\%$ Change from baseline & $-54 \%[-13$ to +70$]$ & $-13 \%[-58$ to +70$]$ & 0.047 \\
\hline \multicolumn{4}{|l|}{ At 14 days } \\
\hline White blood cell, $10^{9} / \mathrm{L}$ & $7.10[5.70-9.40]$ & $8.60[6.92-10.5]$ & \\
\hline$\%$ Change from baseline & $-33 \%[-45$ to -22$]$ & $-20 \%[-41$ to -9$]$ & 0.044 \\
\hline Absolute neutrophil count, $10^{9} / \mathrm{L}$ & $4.60[3.30-5.50]$ & $5.50[4.00-7.15]$ & \\
\hline$\%$ Change from baseline & $-42 \%[-61$ to -25$]$ & $-32 \%[-51 \%$ to -1$]$ & 0.067 \\
\hline Absolute lymphocyte count, $10^{9} / \mathrm{L}$ & $2.10[1.50-2.60]$ & $2.00[1.70-2.27]$ & \\
\hline$\%$ Change from baseline & $0 \%[-32$ to +32$]$ & $+10 \%[-22$ to 40$]$ & 0.313 \\
\hline Absolute monocyte count, $10^{9} / \mathrm{L}$ & $0.60[0.50-0.80]$ & $0.65[0.50-0.70]$ & \\
\hline$\%$ Change from baseline & $-5 \%[-30$ to +26$]$ & $0 \%[-20$ to +3$]$ & 0.989 \\
\hline Absolute eosinophil count, $10^{9} / \mathrm{L}$ & $0.20[0.10-0.30]$ & $0.20[0.20-0.30]$ & \\
\hline$\%$ Change from baseline & $+100 \%[0$ to +200$]$ & $0 \%[-30$ to +100$]$ & 0.043 \\
\hline Neutrophil to lymphocyte ratio & $2.26[1.34-3.25]$ & $2.89[1.93-3.68]$ & \\
\hline$\%$ Change from baseline & $-50 \%[-67$ to 10$]$ & $-36 \%[-65$ to +3$]$ & 0.500 \\
\hline \multicolumn{4}{|l|}{ At 3 months } \\
\hline White blood cell, $10^{9} / \mathrm{L}$ & $6.90[5.90-8.60]$ & $7.55[6.05-9.47]$ & \\
\hline$\%$ Change from baseline & $-41 \%[-49$ to -16$]$ & $-30 \%[-44$ to -19$]$ & 0.301 \\
\hline Absolute neutrophil count, $10^{9} / \mathrm{L}$ & $4.20[3.30-5.20]$ & $4.35[3.50-5.70]$ & \\
\hline$\%$ Change from baseline & $-53 \%[-61$ to -25$]$ & $-43 \%[-54$ to -33$]$ & 0.298 \\
\hline Absolute lymphocyte count, $10^{9} / \mathrm{L}$ & $2.10[1.50-2.60]$ & $2.00[1.57-2.30]$ & \\
\hline$\%$ Change from baseline & $-3 \%[-29$ to +35$]$ & $+8 \%[-28$ to +59$]$ & 0.584 \\
\hline Absolute monocyte count, $10^{9} / \mathrm{L}$ & $0.60[0.50-0.70]$ & $0.65[0.50-0.70]$ & \\
\hline$\%$ Change from baseline & $-10 \%[-28$ to +24$]$ & $7 \%[-30$ to +25$]$ & 0.748 \\
\hline Absolute eosinophil count, $10^{9} / \mathrm{L}$ & $0.20[0.10-0.20]$ & $0.20[0.10-0.32]$ & \\
\hline$\%$ Change from baseline & $0 \%[0$ to 100$]$ & $+33 \%$ [o to $100 \%$ ] & 0.764 \\
\hline
\end{tabular}




\begin{tabular}{|llll|}
\hline & $\begin{array}{l}\text { Anakinra } \\
(\mathbf{n = 6 4})\end{array}$ & $\begin{array}{l}\text { Placebo } \\
(\mathbf{n = 3 5 )}\end{array}$ & $P$-value \\
\hline Neutrophil to lymphocyte ratio & $2.09[1.35-2.85]$ & $2.61[1.73-3.24]$ & \\
\hline \% Change from baseline & $-51 \%[-70$ to 17] & $-42 \%[-75$ to -9$]$ & 0.964 \\
\hline
\end{tabular}

Data are expressed as median [interquartile range]. $P$-values in bold character indicate significant values $(<0.05)$ for difference between groups. Abbreviations: CKMB-AUC: Creatine kinase-MB area under the curve; CRP-AUC: C-reactive protein area under the curve; NTproBNP: N-terminal pro-brain natriuretic peptide.

\section{White Blood Cell Count and Differential Count during STEMI}

Table 2 shows WBC count with differential and other laboratory parameters in the two groups. There were no significant differences in any of the laboratory parameters at baseline. A significant reduction in WBC (11.40 [9.20-15.07] vs 8.30 [7.20-9.80] 10\%/L; -21\% [-34 to -10], $\mathrm{P}<0.001$ within placebo group) and neutrophil count (7.30 [5.20-12.50] vs $5.40[4.65-5.40] 10^{9} / \mathrm{L} ;-27 \%$ [-46 to -5$], \mathrm{P}=0.003$ within placebo group) were seen in the placebo group at 72 hours (Table 2 ).

\section{Effect of Treatment with Anakinra on White Blood Count}

At 72 hours, when compared with placebo, treatment with anakinra led to a statistically significant greater percentage reduction in total WBC count $(-35 \%$ [-48 to -24$]$ vs $-21 \%$ [-34 to -10$], P<0.001$ within anakinra group, and $\mathrm{P}=0.008$ for between groups differences) (Figure 1, Table 2). A significantly greater percentage reduction in WBC count persisted in the anakinra group compared to placebo group at 14 days, while on treatment, and it was no longer seen at 90 days following discontinuation of treatment (Figure 1, Table 2).

\section{Effect of Treatment with Anakinra on Leukocyte Differential Count}

At 72 hours, when compared with placebo, treatment with anakinra led to a statistically significant greater percentage reduction in absolute neutrophil count (-48\% [-60 to -22$]$ vs $-27 \%$ [-46 to -5$], P<0.001$ within anakinra group, and $\mathrm{P}=0.004$ for between groups differences), and neutrophil to lymphocyte ratio (-54\% $[-13$ to +70$]$ vs $-13 \%[-58$ to +70$], P<0.001$ within anakinra group, and $P=0.047$ for between groups differences), and to an increase in absolute eosinophil count (+50\% [0 to +100$]$ vs $0 \%[-50$ to +62$]$, $\mathrm{P}<0.001$ within anakinra group, and $\mathrm{P}=0.022$ for between groups differences)(Figure 1 , Table 2 ). $\mathrm{A}$ significantly greater percentage increase in absolute eosinophil count persisted in the anakinra group 
compared to placebo group at 14 days, while on treatment, and it was no longer seen at 90 days following discontinuation of treatment (Figure 1, Table 2).

\section{Discussion}

We herein report, for the first time in literature, that IL-1 blockade with anakinra leads to a significantly greater reduction of leukocyte count in patients with STEMI, and that it drives a relative greater reduction in neutrophils and an increase in eosinophils. Considered a surrogate for the infiltration of WBC into necrotic tissue in response to ischemia and reperfusion, leukocytosis is a common finding in patients with acute STEMI and portends a poor prognosis (3-6,19-21). Leukocytosis is considered a surrogate for the infiltration of WBC into necrotic tissue in response to ischemia and reperfusion. Neutrophils are the first cells to arrive in the infarcted tissue attracted by the cellular debris and damage-associated molecular patterns generated by the necrotic cells (7-9). Upon arrival, leukocytes become activated and generate reactive oxygen species and proteolytic enzymes - thereby further expanding myocardial injury (7-9). Recently, Sreejit and colleagues showed that neutrophils play a key role in determining the nature and orchestrating the inflammatory response in the heart (9). Once recruited in the myocardium, activated neutrophils may release various proteins that prime the Nod-Like-Receptor (NLR) family Pyrin DomainContaining 3 (NLRP3) inflammasome-a multi-molecular platform crucial to induction of the inflammatory response to cellular danger-on naïve neutrophils and stimulate them to produce IL-1 $\beta$ locally. This local production interacts with the IL-1 receptor type I (IL-1 $\left.\mathrm{R}_{\mathrm{l}}\right)$ on hematopoietic stem cells in the bone marrow, stimulating myelopoiesis in a cell-intrinsic manner and amplify the granulopoiesis (9). Unopposed IL-1 activity during myocardial infarctions mobilizes myeloid cells from bone marrow to the infarction site inducing pathological myocardial healing and favoring cardiac rupture in experimental models $(5,20)$. During acute myocardial infarction, an increased expression of the IL-1 $\mathrm{R}_{\mid}$was found, suggesting that the upregulation of IL-1R may facilitate neutrophil proliferation and differentiation (9). Furthermore, IL-1 stimulates the calcium-dependent degranulation of neutrophils and release of proteases (e.g. cathepsin G, elastase, and proteinase) that may contribute to the proteolytic break down of necrotic myocytes and extracellular matrix, and to cleave and activate multiple IL-1 family members (22). Of note, IL-1 is sufficient to induce a cardiomyopathy phenotype in the mouse (23).

From a translational point of view, in the VCUART phase II clinical trial program that included 3 studies $(n=139)(15,17,24,25)$ of patients with STEMI treated with anakinra resulted in a significant improvement in left ventricular performance and a significant reduction of new-onset heart failure and of heart failure hospitalization versus placebo. Similarly, the CANTOS trial enrolling patients with previous acute myocardial infarction and persistent inflammation found that canakinumab (an IL-1 $\beta$ blocker) resulted in a reduction in the hospitalizations for heart failure (26).

We also found that treatment with anakinra led to a significant increase in circulating eosinophils. Eosinophilia is reported in $9 \%$ of patients using anakinra in clinical practice (27). The underlying mechanisms are not known. However, eosinophils have recently emerged to play an important role in infarct healing. Eosinophil recruitment within the myocardium may assist in mitigating the cardiac 
inflammatory cell profile, limiting cardiomyocyte apoptosis, modulating fibroblast activity, and regulating post myocardial infarction heart inflammatory cell adhesion and infiltration (28). Whether the benefits of anakinra in modulating the inflammatory response and preventing post-STEMI heart failure is also related to an effect on eosinophils is unknown.

The small sample size of the study population and the post-hoc nature of the analysis represent the major limitations of this report. The white blood cell count with differential count is also an approximate measure of leukocyte populations with no insight in the subpopulations thus limiting the ability to fully understand the process. Furthermore, we did not measure values of WBC count and its differential count at 12 and 24 hours, when a peak in leukocytes and neutrophils is expected during STEMI (3), and we may be therefore unable to assess the effect of anakinra on leukocyte in the early phase during STEMI and to fully appraise the effects of anakinra.

In conclusion, IL-1 blockade with anakinra resulted in a greater reduction of leukocyte count in patients with STEMI, with a relative reduction in neutrophils and increase in eosinophils. These data support the pathophysiologic role of IL-1 in the leukopoiesis in acute myocardial infarction and support the role of therapeutic strategies aiming at reducing IL-1 signaling or inhibiting the upstream inflammasome to target inflammation and improve infarct healing and outcomes in STEMI.

\section{Declarations}

\section{Author contributions}

Giuseppe G. Biondi-Zoccai, Michael C. Kontos, Benjamin W. Van Tassell and Antonio Abbat contributed to the study conception and design. Material preparation and data collection was performed by all the authors. Analysis were performed by Marco Del Buono, Juani Damonte and An tonio Abbate. The first draft of the manuscript was written by Marco G. Del Buono, Juani Damonte and all authors commented on previous versions of the manuscript. All authors read and approved the final manuscript.

Funding VCUART3 The study was supported by a grant from the National Institutes of Health (1R34HL121402-01) to Drs. Abbate and Van Tassell. Swedish Orphan Biovitrum provided drug and placebo for VCUART3. Dr. Abbate received support from the 'Sapienza Visiting Professor Programme 2020" of the Sapienza Università di Roma, Italy.

Disclosures: Drs. Abbate and Van Tassell have served as consultants to Swedish Orphan Biovitrum LLC in the past. The remaining authors have no disclosures to report.

\section{References}

1. Kristensen SD, Laut KG, Fajadet J, et al. Reperfusion therapy for ST elevation acute myocardial infarction 2010/2011: current status in 37 ESC countries [published correction appears in Eur Heart J. 2014 Oct 7,35(38):2697]. Eur Heart J. 2014,35(29):1957-1970. doi:10.1093/eurheartj/eht529. 
2. Toldo S, Abbate A. The NLRP3 inflammasome in acute myocardial infarction. Nat Rev Cardiol. 2018,15(4):203-214. doi:10.1038/nrcardio.2017.161

3. Kirtane AJ, Bui A, Murphy SA, Barron HV, Gibson CM. Association of peripheral neutrophilia with adverse angiographic outcomes in ST-elevation myocardial infarction. Am J Cardiol. 2004,93(5):532536. doi:10.1016/j.amjcard.2003.11.013

4. Kyne L, Hausdorff JM, Knight E, Dukas L, Azhar G, Wei JY. Neutrophilia and congestive heart failure after acute myocardial infarction. Am Heart J. 2000,139(1 Pt 1):94-100. doi:10.1016/s00028703(00)90314-4

5. O'Donoghue M, Morrow DA, Cannon CP, et al. Association between baseline neutrophil count, clopidogrel therapy, and clinical and angiographic outcomes in patients with ST-elevation myocardial infarction receiving fibrinolytic therapy. Eur Heart J. 2008,29(8):984-991. doi:10.1093/eurheartj/ehn112

6. Seropian IM, Sonnino C, Van Tassell BW, Biasucci LM, Abbate A. Inflammatory markers in STelevation acute myocardial infarction. Eur Heart J Acute Cardiovasc Care. 2016 Aug,5(4):382-95. doi: $10.1177 / 2048872615568965$.

7. Nahrendorf M, Swirski FK, Aikawa E, et al. The healing myocardium sequentially mobilizes two monocyte subsets with divergent and complementary functions. J Exp Med. 2007,204(12):30373047. doi:10.1084/jem. 20070885

8. Horckmans M, Ring L, Duchene J, et al. Neutrophils orchestrate post-myocardial infarction healing by polarizing macrophages towards a reparative phenotype. Eur Heart J. 2017,38(3):187-197. doi:10.1093/eurheartj/ehw002

9. Sreejit G, Abdel-Latif A, Athmanathan B, et al. Neutrophil-Derived S100A8/A9 Amplify Granulopoiesis After Myocardial Infarction. Circulation. 2020,141(13):1080-1094. doi:10.1161/CIRCULATIONAHA.119.043833

10. Frangogiannis NG. The inflammatory response in myocardial injury, repair, and remodelling. Nat Rev Cardiol. 2014,11(5):255-265. doi:10.1038/nrcardio.2014.28

11. Toldo S, Mezzaroma E, Mauro AG, Salloum F, Van Tassell BW, Abbate A. The inflammasome in myocardial injury and cardiac remodeling. Antioxid Redox Signal. 2015,22(13):1146-1161. doi:10.1089/ars.2014.5989

12. Toldo S, Marchetti C, Mauro AG, et al. Inhibition of the NLRP3 inflammasome limits the inflammatory injury following myocardial ischemia-reperfusion in the mouse. Int J Cardiol. 2016,209:215-220. doi:10.1016/j.ijcard.2016.02.043

13. Toldo S, Mauro AG, Cutter Z, Abbate A. Inflammasome, pyroptosis, and cytokines in myocardial ischemia-reperfusion injury. Am J Physiol Heart Circ Physiol. 2018,315(6):H1553-H1568. doi:10.1152/ajpheart.00158.2018

14. Sager HB, Heidt T, Hulsmans $M$, et al. Targeting Interleukin-1 $\beta$ Reduces Leukocyte Production After Acute Myocardial Infarction. Circulation. 2015,132(20):1880-1890. doi:10.1161/CIRCULATIONAHA.115.016160 
15. Abbate A, Kontos MC, Grizzard JD, et al. Interleukin-1 blockade with anakinra to prevent adverse cardiac remodeling after acute myocardial infarction (Virginia Commonwealth University Anakinra Remodeling Trial [VCU-ART] Pilot study). Am J Cardiol. 2010,105(10):1371-1377.e1. doi:10.1016/j.amjcard.2009.12.059.

16. Sonnino C, Christopher S, Oddi C, et al. Leukocyte activity in patients with ST-segment elevation acute myocardial infarction treated with anakinra. Mol Med. 2014,20(1):486-489.. doi:10.2119/molmed.2014.00121

17. Abbate A, Trankle CR, Buckley LF, et al. Interleukin-1 Blockade Inhibits the Acute Inflammatory Response in Patients With ST-Segment-Elevation Myocardial Infarction. J Am Heart Assoc. 2020,9(5):e014941. doi:10.1161/JAHA.119.014941

18. Van Tassell BW, Lipinski MJ, Appleton D, et al. Rationale and design of the Virginia Commonwealth University-Anakinra Remodeling Trial-3 (VCU-ART3): A randomized, placebo-controlled, doubleblinded, multicenter study. Clin Cardiol. 2018,41(8):1004-1008. doi:10.1002/clc.22988

19. Chia S, Nagurney JT, Brown DF, et al. Association of leukocyte and neutrophil counts with infarct size, left ventricular function and outcomes after percutaneous coronary intervention for ST-elevation myocardial infarction. Am J Cardiol. 2009,103(3):333-337. doi:10.1016/j.amjcard.2008.09.085

20. Abbate A, Salloum FN, Van Tassell BW, et al. Alterations in the interleukin-1/interleukin-1 receptor antagonist balance modulate cardiac remodeling following myocardial infarction in the mouse. PLoS One. 2011,6(11):e27923. doi:10.1371/journal.pone.0027923

21. Núñez J, Núñez E, Bodí $V$, et al. Usefulness of the neutrophil to lymphocyte ratio in predicting longterm mortality in ST segment elevation myocardial infarction. Am J Cardiol. 2008,101(6):747-752. doi:10.1016/j.amjcard.2007.11.004

22. Smith RJ, Bowman BJ, Speziale SC. Interleukin-1 stimulates granule exocytosis from human neutrophils. Int J Immunopharmacol. 1986,8(1):33-40. doi:10.1016/0192-0561(86)90070-6

23. Van Tassell BW, Seropian IM, Toldo S, Mezzaroma E, Abbate A. Interleukin-1 $\beta$ induces a reversible cardiomyopathy in the mouse. Inflamm Res. 2013,62(7):637-640. doi:10.1007/s00011-013-0625-0

24. Abbate A, Van Tassell BW, Biondi-Zoccai G, et al. Effects of interleukin-1 blockade with anakinra on adverse cardiac remodeling and heart failure after acute myocardial infarction [from the Virginia Commonwealth University-Anakinra Remodeling Trial (2) (VCU-ART2) pilot study]. Am J Cardiol. 2013,111(10):1394-1400. doi:10.1016/j.amjcard.2013.01.287

25. Abbate A, Kontos MC, Abouzaki NA, et al. Comparative safety of interleukin-1 blockade with anakinra in patients with ST-segment elevation acute myocardial infarction (from the VCU-ART and VCU-ART2 pilot studies). Am J Cardiol. 2015,115(3):288-292. doi:10.1016/j.amjcard.2014.11.003

26. Everett BM, Cornel JH, Lainscak M, et al. Anti-Inflammatory Therapy With Canakinumab for the Prevention of Hospitalization for Heart Failure. Circulation. 2019,139(10):1289-1299. doi:10.1161/CIRCULATIONAHA.118.038010

27. https://www.accessdata.fda.gov/drugsatfda_docs/label/2012/103950s5136lbl.pdf 


\section{Figures}
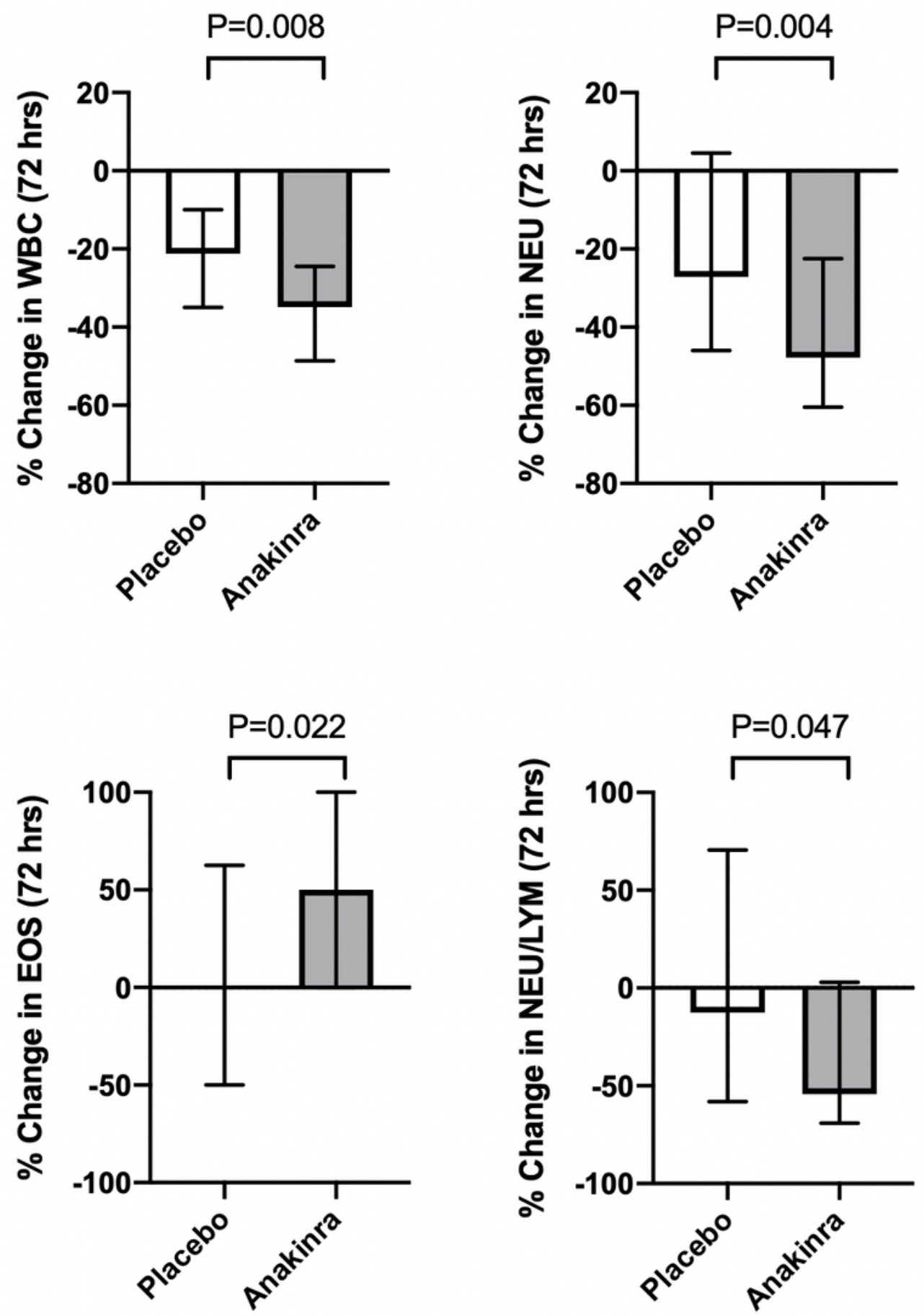

Figure 1 
Percentage (\%) change from baseline to 72 hours in white blood cell count (WBC, panel A), absolute neutrophil count (NEU, panel B), absolute eosinophils count (EOS, panel C) and neutrophil to lymphocyte ratio (NEU/LYM, panel $D)$ in the anakinra $(n=64)$ versus placebo group $(n=35)$. 